\title{
A PRÁTICA E OCORRÊNCIA DO BULLYING NA ESCOLA
}

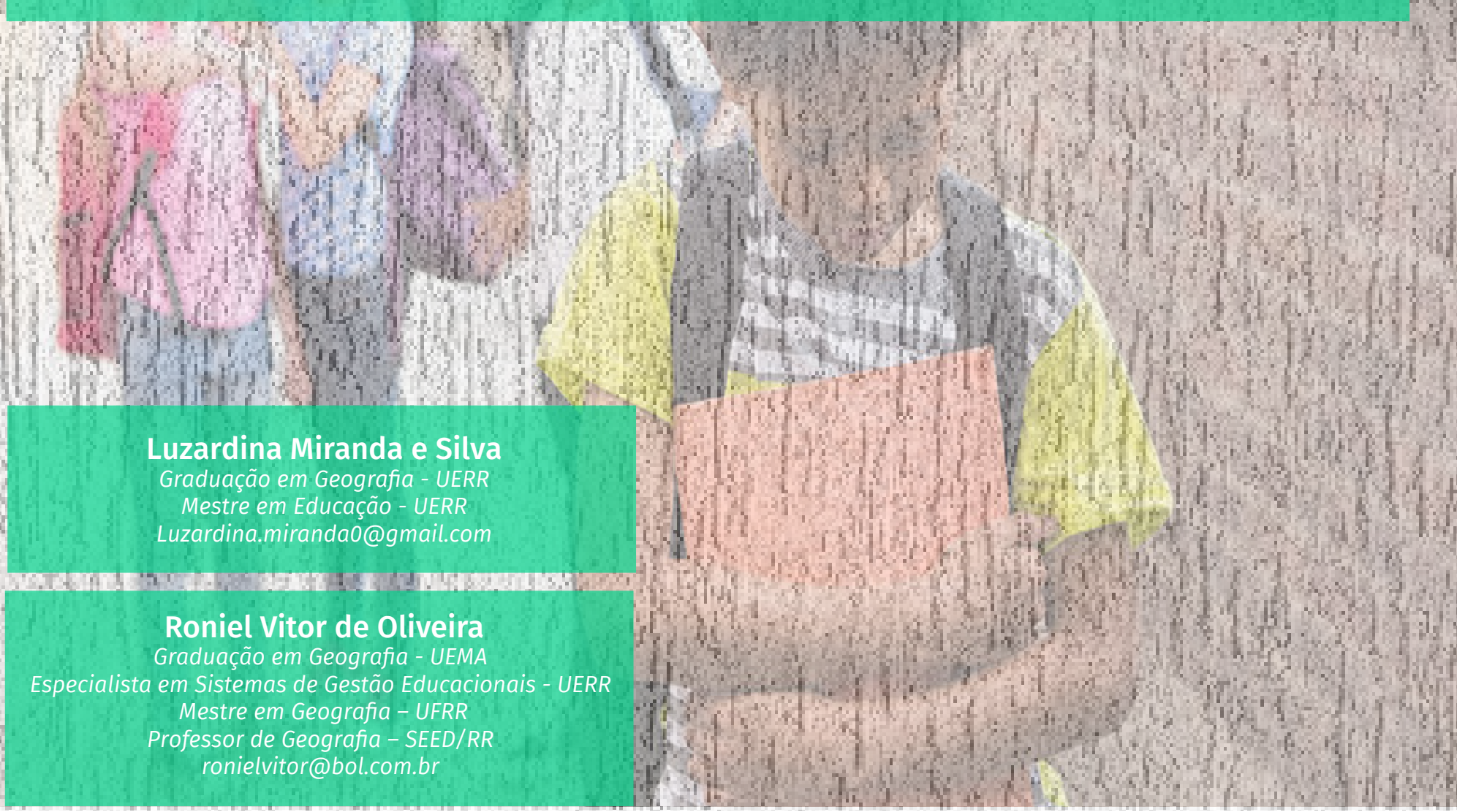

\section{RESUMO}

O presente artigo se propõe a fazer uma análise e reflexão sobre um tema de suma importância na atualidade, o bullying, um dos problemas que tem afligido muitas pessoas na sociedade em geral. No ambiente escolar, tem se acentuado em decorrência da intolerância com as diferenças existentes entre o público de alunos. O Bullying existe entre todas as idades, especialmente entre o público adolescente que surge em sua forma discriminatória, com ameaças, intimidações, apelidos vexatórios e dentre outras formas de agressão e constrangimento, podendo conduzir as vítimas a estado de isolamento e desmotivação para frequentar a escola. Nas escolas de ensino integral, onde o convívio torna-se mais frequente pelo tempo que os alunos passam convivendo no mesmo ambiente, esse problema pode apresentar-se mais acentuado. 0 objetivo da pesquisa apresentada neste trabalho foi investigar a prática e ocorrência do bullying em uma escola de ensino integral do município de Rorainópolis- RR. Para tanto, teve como aporte metodológico a aplicação de 70 questionários junto ao público discente, sendo que os participantes eram $55 \%$ constituído por indivíduos do sexo feminino e $45 \%$ eram do sexo masculino. Ademais foi realizado levantamento bibliográfico acerca da temática e uma entrevista com a gestão da escola. Os resultados da pesquisa demonstram que os participantes possuem conhecimento do bullying, já foram vítimas e também já estiveram na posição de praticantes dessa violência. Estima-se que os resultados dessa pesquisa possam direcionar escola, sociedade e família para minimizar a ocorrência do bullying, principalmente pelo fortalecimento das relações entre os atores que compõem a escola com o objetivo de reduzir os casos existentes e que ainda poderão ocorrer.

Palavras - chave: Educação Inclusiva; Geografia e Alunos com deficiência.
This article proposes to make an analysis and reflection on a topic of great importance in the present, bullying, one of the problems that has afflicted many people in the society in general. In the school environment, it has been accentuated by the intolerance of differences among the students' public. Bullying exists among all ages, especially among the adolescent public that appears in its discriminatory form, with threats, intimidation, vexatious nicknames and among other forms of aggression and embarrassment, and can lead the victims to a state of isolation and demotivation to attend school . In the schools of integral education, where the conviviality becomes more frequent by the time that the students spend coexisting in the same environment, this problem can appear more accentuated. The objective of the research presented in this study was to investigate the practice and occurrence of bullying in a comprehensive school of the municipality of Rorainópolis-RR. To that end, the methodological contribution was the application of 70 questionnaires to the student population, of which $55 \%$ were female and $45 \%$ were male. In addition, a bibliographic survey about the subject and an interview with the management of the school were carried out. The results of the research demonstrate that the participants have knowledge of bullying, have already been victims and have also been in the position of practicing this violence. It is estimated that the results of this research can direct school, society and family to minimize the occurrence of bullying, mainly by strengthening the relationships between the actors that make up the school in order to reduce existing cases and that may still occur.

Key - words: Bullying, Violence. School. 


\section{INTRODUÇÃO}

O bullying surge como uma modalidade de violência ocorrida principalmente entre o público jovem e no interior da escola. Os casos desse tipo de violência não são raros e tornaram-se comuns. Ocorre a partir da agressão física ou psicológica em desfavor de uma vítima. Segundo Zaquenão (2016), possui a intenção de ferir, magoar ou diminuir moralmente a vítima. As agressões sejam elas físicas ou psicológicas podem ser oriundas de grupos ou ações individuais com tapas, empurrões, pontapés, cuspes, roubos, estragos de objetos e até a submissão do outro a atividades servis, hostilizando a imagem da vítima.

A violência ocorrida por intermédio do que se denomina bullying constitui, segundo Clementino et. Al (2018), um problema de saúde pública complexo, e que requer investimentos científicos e políticos para ampliação das discussões sobre o fato e possivel resolução. Não obstante, compromete também o desempenho escolar e contribui para a evasão de alunos.

Diante desse problema, que integra a vida cotidiana das escolas e apresenta dados negativos, surgiu à proposta de investigar a ocorrência do bullying numa de Ensino Integral do Município de Rorainópolis, visto que, quando a escola funcionava somente na modalidade de ensino regular a convivência entre os alunos se dava somente em um turno, ou seja, 4 horas diárias.

A respeito da pesquisa, que traz como título a prática e ocorrência do bullying na escola, busca compreendermos que a pessoa submetida a essa prática, sofre independente de sua classe social, religiosa, econômica entre outras, vários tipos de preconceito, mostrando assim as suas varias faces deste ato de agressividade. A prática bullying submete as vítimas às diversas formas de maus-tratos psicológicos, verbais, fisicos, morais, sexuais e materiais, apelidos pejorativos, difamações, ameaças, perseguições, exclusões.

Os atos agressivos se tornam repetitivos e intencionais sem motivação evidente gerando na escola e na sala de aula relações desiguais de poder caracterizam o bullying escolar, este trabalho foi desenvolvido para buscarmos mais atenção perante esse assunto, muitas vezes deixado de lado, criar inquietações diante de um tema tão contemporâneo em nosso contexto.

\section{METODOLOGIA}

Os resultados que integram este trabalho são fruto de uma pesquisa aplicada junto ao público discente e gestão escolar de uma escola pública de nível médio integral do município de Rorainópolis - RR. Optouse por não revelar o nome da instituição de ensino tendo em vista a necessidade de resguardar sua imagem e, por conseguinte os participantes da pesquisa. No que tange aos objetivos, a pesquisa foi classificada como descritiva. Para Gil (2009, p. 42.) “As pesquisas descritivas têm como objetivo primordial a descrição das características de determinada população ou fenômeno [...].". Em relação à abordagem dos procedimentos técnicos utilizados constitui-se em um estudo de caso, conforme Gil (2009, p.54) o estudo de caso tem como propósito "o de proporcionar uma visão global do problema ou de identificar possiveis fatores que o influenciam ou são por ele influenciados".

Optou-se ainda por realizar levantamento bibliográfico na busca de fundamentação teórica para compreensão e interpretação da temática e discussão dos dados, pesquisa documental direcionada para o projeto Político Pedagógico da escola e aplicação de 70 questionários junto ao corpo discente e entrevista junto à gestão da escola. A técnica utilizada para seleção da amostra foi a não probabilística, seguindo-se de um universo de 682 alunos, dos turnos matutino, vespertino e noturno, turmas do ensino médio 10 ao 3 o 
ano. Os questionários continham 7 (sete) perguntas, entre objetivas e subjetivas.

\section{RESULTADOS E DISCUSSÕES}

\section{Fundamentação Teórica}

A palavra bullying, de origem inglesa, é usada para designar diversas formas de violência que se caracteriza pelo poder interpessoal que o agressor exerce sobre a vítima, ao mesmo tempo que prática ações para agredi-la, intimidá-la e maltratá-la visando inferiorizar a vítima, produzindo uma relação desigual de poder (CLEMENTINO ET. $A L, 2018)$.

Os debates sobre o bullying possuem na atualidade abrangência internacional, no Brasil medidas mitigadoras são criadas, haja vista, que nos últimos anos houve um elevado crescimento do bullying em niveis escolares e como medida emergencial foi criado à lei do bullying no 13.185/2015, que considera intimidação sistemática (bullying) todo ato de violência física ou psicológica e intencional causando dor e angústia à vítima, em uma relação de desequilíbrio de poder entre as partes envolvidas, (BRASIL, 2015).

Para complementar a prática de combate ao bullying nas instituições de ensino foi criado a Lei № 13.663, DE 14 DE MAIO DE 2018, esta veio para alterar o art. 12 da Lei no 9.394, de 20 de dezembro de 1996, para incluir a promoção de medidas de conscientização, de prevenção e de combate a todos os tipos de violência e a promoção da cultura de paz entre as incumbências dos estabelecimentos de ensino (BRASIL, 2018).

Art. 10 O caput do art. 12 da Lei no 9.394, de 20 de dezembro de 1996, passa a vigorar acrescido dos seguintes incisos IX e X:Art. 12. IX-promover medidas de conscientização, de prevenção e de combate a todos os tipos de violência, especialmente a intimidação sistemática (bullying), no âmbito das escolas;

$X$ - estabelecer ações destinadas a promover a cultura de paz nas escolas.
Assim sendo, os programas de prevenção de combate a este tipo de violência deverão associar-se a estratégias de educação para a cidadania e, tendo em conta a sua importância para a promoção da convivência social positiva e de climas relacionais propícios às aprendizagens, envolver toda a comunidade, (MARTINS, 2011). Envolver a comunidade escolar para combater o bullying é uma das opções mais relevante, visto que ainda não existe uma norma que o defina esta prática e que coiba, como afirma, Santos e Silva (2017), em seu trabalho bullying escolar: ausente na norma, presente na vida. Segundo estes autores falta uma lei federal que coiba a prática do bullying.

O bullying escolar, na esfera cível a vítima tem direito constitucional de requerer reparação judicial, e o autor, além de reparar, pode ser responsabilizado penalmente, caso sua conduta seja típica, ilícita e culpável. Neste caso destaca se:

Caso o praticante seja maior de idade, a responsabilidade obviamente será subjetiva, entretanto viemos demonstrando e é sabido que as práticas de bullying ocorrem principalmente no ambiente escolar e entre crianças e adolescentes, na maioria das vezes menores de idade. Nesta situação a responsabilidade adotada será a solidária, de forma em que os pais responsáveis terão que se submeter a responder pela prática do menor. (SANTOS e SILVA, p. 22, 2017).

\section{(}

Como normalmente a maioria dos infratores são crianças e adolescentes, neste caso o Estatuto da Criança e do Adolescente (ECA) aborda claramente que menores de 18 (dezoito) anos ao cometer ato infracional será aplicado a eleuma medida sócioeducativa, que pode até chegar a ser privativas de liberdade, como observamos. 
Art. 112 - Verificada a prática de ato infracional, a autoridade competente poderá aplicar ao adolescente as seguintes medidas:

I- Advertência; II- Obrigação de reparar o dano; III- Prestação de serviços à comunidade; IV- Liberdade assistida; $V$ - Inserção em regime de semi-liberdade; VI-Internação em estabelecimento educacional; VII- Qualquer uma das previtas no art. 101, I a VI. (BRASIL, 1990).

Nesse caso, vale ressaltar, que para que o bullying seja tipificado como crime, este deve estar de acordo com os princípios do Estatuto da Criança e do Adolescente, como destacado acima (SANTOS e SILVA, 2017). Conforme Silva e Borges (2018, p. 29).

Esse é um problema mundial presente em praticamente todas as instituições de ensino, mas que ainda é um problema desconhecido pelos pais e pela sociedade em geral e por muitas vezes também é ignorado por parte das escolas brasileiras. A comunidade escolar não se sente preparada para lidar com esse tipo de violência e escolhem se omitir quando a toda problemática enfrentada cotidianamente.

A escola públca brasileira é constituída por uma heterogeneidade de indivíduos, que vindos da mesma realidade do mundo capitalista compartilham de suas similaridades ao mesmo tempo que, guardam em si singularidades oriundas de sua vivência particular com a família. A própria contituição da população barsielira representa uma heterogeineidade, mas a principal causa dessas diferenças entre as pessoas são resultantes das relações de trabalho, economia e renda, que se estabelecem no seio da sociedade capitalista competitiva, onde um grupo hegemônico prevalece sobre grupos econômicos inferiores, impôe um modo de vida e constituem as relações de um indivíduo sobre o outro.
Conforme dados do IBGE (2010) a população brasileira é composta basicamente pelas raças branca, preta, amarela, parda e indígena. Toda essa mistura de raças é resultante da presença de três principais grupos etnicos, os indígenas, os africanos e os europeus. Ressalta-se que a colonização do Brasil dizimou parte dos povos indígenas e a presença do africano deve-se a escravidão do negro. O estado brasileiro apresenta ainda, como resultado da variedade étnica, diversas línguas e religiões. De acordo com o IBGE (2010), há no Brasil cerca de 274 línguas inígenas e a presença das religiões Católica Apostólica Romana, Evangélca, Espírita, Umbanda e Candomblé. Não pretende-se neste trabalho fazer uma discussão sobre a composição étnica da população brasileira, mas comprender que toda essa variedade étnica, linguística e religiosa traduz os individuos que frequentam a escola, haja vista que são eles que compõem a população brasileira. Não obstante, o preconceito entre uma raça e outra é frequente, principalmente no que tange ao negro e ao indígena. Segundo Callinicos (1995) o racismo surgiu com a repressão dos negros ao serem escravizados no século XVII e XVIII. Essa escravidão foi à base para formação do sistema capitalista no mundo. Heringer (2002) ressalta que, nesse contexto, apesar de o Brasil já ter sido considerado por várias décadas como o país da democracia racial, o negro ainda ocupa a posição de subalterno e possui baixa escolaridade em relação ao branco, sendo que a população branca apresenta dois anos de estudo a mais que os negros.

A forma como a sociedade trata seus pares, sejam eles negros, indigenas, brancos, homossexuais, deficientes, entre outros, está presente no cotidiano da escola, ou seja, todo o preconceito contra esses grupos sociais ocorre em vários espaços e a escola não está excluída desse rol. Com a difusão dos meios técnicos informacionais, como a internet, tem ganhado proporções maiores e atingido em 
massa grande número de pessoas, na escola inclusive pode prejudicar o desempenho escolar de crianças e jovens.

Segundo, Lopes Neto (2005, p.4), o autor de bullying é aquele "tipicamente popular; tende a envolver-se em uma variedade de comportamentos antissociais; pode mostrarse agressivo inclusive com os adultos; é impulsivo; vê sua agressividade como qualidade [...]". O mesmo autor ainda contribui afirmando que "são menos satisfeitos com a escola e a família, mais propensos ao absenteísmo e à evasão escolar e têm uma tendência maior para apresentarem comportamentos de risco (consumir tabaco, álcool ou outras drogas, portar armas, brigar".

\section{RESULTADOS}

Conforme os dados pesquisados $55 \%$ dos entrevistados eram do sexo feminino, juntamente com $45 \%$ do sexo masculino. Sendo que a média de idade era entre $14 \mathrm{e}$ 18 anos. Os participantes da pesquisa eram $45 \%$ da zona urbana e $55 \%$ oriundos da zona rural. Ressalta-se ainda que, conforme dados do Projeto Político Pedagógico da instituição (PPP), os discentes atendidos são em sua maioria filhos de agricultores, funcionários públicos, microempresários e autônomos.

Ressalta ainda o PPP (2013), que a maioria dos alunos atendidos pela escola são católicos com um total de $41 \%$, o grupo de evangélicos surge em seguida sendo praticado por $34 \%$ dos alunos e os demais são praticantes de outras religiões. Cerca de $65 \%$ dos alunos são de cor parda, seguida da branca com 19\%, a preta com $13 \%$, a indígena com $1 \%$ e as demais não declaradas.

Diante das peculiaridades de cada indivíduo, a escola precisa necessariamente manter o foco do seu objetivo. Conforme Saviani (2013), a escola possui uma função social primordial na sociedade, a de proporcionar aos educandos meios de acesso ao conhecimento humano em suas formas mais desenvolvidas, bem como em seus rudimentos, caracterizando-se pela disseminação do conhecimento científico sistematizado que deve fundamentar as atividades da escola. A função clássica da escola constitui-se na transmissãoassimilação do saber sistematizado. Diante do exposto, sente-se a função que a escola possui frente à problemática do bullying, em estudar e difundir o conhecimento na sua forma sistematizada de forma a contribuir com o esclarecimento das problemáticas que surgem no interior da escola e da sociedade.

A pesquisa ora realizada aponta que, o bullying não constitui um fenômeno desconhecido ou isolado do ambiente escolar em questão, ao serem interrogados se conhecem ou desconhecem o bullying, obteve-se o resultado que $100 \%$ dos alunos já ouviram falar. Na mesma questão, foi indagado o que para eles configura bullying, desta forma os relatos apontaram para o mesmo sentido, sendo resumido em uma agressão contra outra pessoa com apelidos e tratamentos vexatórios, agressões verbais, psicológicas e física. Conforme Zequinão et. al (2016) nem todas as agressões são consideradas como bullying, e a prática constitui um impacto na vida das vítimas dessa violência, para ser definida como tal a prática deve apresentar quatro características a saber: intenção do autor da violência em ferir o alvo em específico, a agressão deve repetir-se na presença de público expectador, ademais o alvo das provocações violentas deve necessariamente concordar com as provocações, acuados.

A pesquisa aponta ainda, conforme os dados da segunda pergunta do questionário, que $77 \%$ dos participantes da pesquisa afirmam já terem sofrido bullying na escola, enquanto $23 \%$ afirmam nunca terem sido vítimas. O bullying constitui uma prática antiga, em que muitas crianças e adolescentes já foram vítimas e continuam sendo, porém por caracterizar uma prática comum na fase infantil e adolescente esse debate já esteve 
em segundo plano sob a alegação de que seria apenas mais uma atitude imatura de adolescentes. Para Bock (2004), a adolescência possui a imagem de uma fase imatura, em que as atitudes são dadas como bobagens. Entretanto, o discurso acerca da temática do bullying tem ocupado mais espaço nas diversas áreas do conhecimento por entender que afeta diretamente o desempenho escolar e o desenvolvimento psicológico das crianças e adolescentes.

Sobre o bullying constituir uma agressão, $100 \%$ dos participantes responderam que é uma agressão que afeta diretamente e de forma negativa a vida das vítimas. Conforme Grillo e Santos (2015. p. 62), "o Bullying se estabelece como uma violência onde há uma relação desigual de poder, isto é, o agressor tem poder sobre a vítima". Não obstante, as manifestações de violência afetam a vítima de forma negativa, podendo além de reduzir seu desempenho escolar, encaminhá-la para um quadro de depressão, conforme afirma (CALDAS, 2017), para a autora, casos de bullying têm desencadeado diversos transtornos psicológicos em quem passa, como: ansiedade, depressão, em casos mais extremos faz o individuo humilhado cometer suicídio. Nesse contexto, essa prática de violência não pode ser legitimada apenas como uma atitude infantil de adolescentes imaturos é um crime que deve ser combatido.

As interrogações sobre a prática do bullying pelos participantes apontou que $100 \%$ do grupo de interrogados já praticou algum ato atentatório e violento contra os colegas, reconhecido pelos agressores como sendo bullying. Um precedente muito grave, haja vista que, na pergunta anterior houve unanimidade ao afirmarem que consideram tal prática como uma forma de agressão e mesmo sabendo disso continuam a praticar. Tal afirmação conduz a discussão de quais seriam as motivações para que esses adolescentes praticassem bullying, mesmo sabendo que constitui uma violência contra seus pares.
Seguindo a mesma linha de interpretação exposta acima, quanto aos danos provocados. Os participantes responderam se a prática do bullying pode fazer com que a vitima possa para de estudar. Quanto a isso os resultados foram unânimes, $100 \%$ responderam que, a prática do bullying pode sim desestimular a vítima a estudar ou até mesmo desistir da escola. Sobre isso, Nikodem e Piber (2017. p. 106), afirmam que "devido ao bullying, muitos alunos abandonam a escola na tentativa de livrar-se das pressões sofridas, o que não resolve o problema, pois os efeitos do bullying já estão presentes em sua vida". Os mesmos autores, ainda contribuem quando falam que "outros a abandonam aos poucos, faltando às aulas por medo de serem as próximas vítimas". Trabalhando na ótica da prevenção contra esses atos atentatórios a moral e imagem dos indivíduos e ainda violentos, Ventura e Fante (2011, p. 21), ressalta que a "melhor forma de combate à prática do Bullying é a busca de planos, ações e medidas que visem à sua conscientização e prevenção". Em atenção às diversidades sociais, culturais e econômicas de cada instituição de ensino".

Pensando nesse sentido, vislumbras-se a necessidade de o poder público, sociedade e escola trabalharem conjuntamente na busca de superação desses problemas que ocorrem no interior da escola, mas tem suas origens nos fundamentos da construção da sociedade.

A abordagem dos questionários, finalizou suas interrogações perguntando como o bullying pode ser combatido no ambiente escolar. As respostas direcionaram-se para busca de apoio profissional, como ajuda de psicólogo, conforme aponta o depoimento do participante A "procurando piscólogo e ajuda aos amigos". Não obstante, os demais participantes acreditam na resolução da problemática e buscam diferentes amparos para resolver, conforme narração de $B$ "com projeto, palestras e dinâmicas de conscientização" e também do participante C "com respeito as pessoas". Silva e Borges 
(2018), acreditam que o enfrentamento no cobate ao bullying deve envolver uma parceria contínua entre os pais e a escola, buscando uma comunicação adequada com os filhos para capacitá-los diante dessa situação.

O bullying é um problema de toda a sociedade, pois violências consideradas de menor potencial podem alcançar proporções maiores de dificil controle, assim, é importante que toda a sociedade trabalhe no combate a violência, principlamente no ambiente escolar. Pensando no papel que a escola desempenha frente a essa problemática, que a entrevista realizada com a gestão escolar direcionou-se, para investigar as iniciativas da escola de combate a essa prática. Conforme os depoimentos disponibilizados durante a entrevista, restou esclarecido que a escola não possui um projeto específico e contínuo de combte ao bullying, haja vista que a disponibilidade de recursos e profissionais especializados na área é precária no ambiente escolar público, entretanto, a instituição direcionou diversas ações ao longo do ano letivo na tentativa de corroborar com a diminuição dos casos de bullying entre os adolescentes.

Neste sentido, indagamos a gestão da escola, se esta já recebeu alguma denúncia de ocorrência de bullying, a resposta foi que sim, e ressaltou que o procedimento tomado para tentar resolver o problema foi o diálogo entre as partes, conforme aponta os relatos

Chamamos os envolvidos para conversarmos explicando os problemas gravissímos dessa atitude que pode causar grandes danos para o outro. Após o término da conversa fomos todos na sala de aula dos envolvidos onde o mesmo pediu desculpas para o colega. Neste contexto, eu gestora fiz varias considerações com a temática tais como: respetio ao proximo, desigualdades sociais, valores dentre outros.

do participante C:
Diante de tal circunstância, é de suma importância que a escola crie uma fonte de diálogo entre aluno e a instituição para que ele se sinta protegido e compreendido para assim, levar a conhecimento da direção todos os problemas e dificuldades por eles sofridos (SILVA e BORGES, 2018). Ademais, sente-se que ainda há necessidade de família, escola e sociedade trabalharem juntas em um projeto de combate as formas de discriminação e violência que envolvem as crianças e adolescentes.

\section{CONSIDERAÇÕES FINAIS}

O combate ao bullying, como proposto nesta pesquisa deve envolver todos os segmentos da sociedade, sendo que, cada um deve fazer a parte que lhe cabe neste acontecimento, aspectos que vai desde os pais educando os filhos os princípios éticos e morais, e a escola estabelecendo projetos educacionais voltados para o combate a esse ato cada vez mais nocivos as criança e os adolescente.

A presente pesquisa sobre a prática e ocorrencia do bullying na escola, foi desenvolvida numa escola de Ensino Integral do Municipio de Rorainópolis - Roraima, se justifica porque tal prática está fazendo com que o desempenho de muitos alunos em situações de violência venha a ser comprometida. Igualmente, o bullying diz respeito a uma forma de afirmação de poder interpessoal através da agressão, onde a vitima pode sofrer por toda a sua vida em consequência deste ato.

As consequências provocadas pelo bullying são graves, afetam crianças e adolescentes que convivem com esse tipo de violência, comprometendo desta forma, seu rendimento na escola e na vida social. Podemos analisar que estas formas de agressões estão relacionadas a prática do racismo, assédio moral, psicológico, sexual, entre outros. 
Os apelidos às vezes considerados inofensivos trazem consequências devastadoras para a pessoa agredida. Dessa forma, torna-se urgente projetos educacionais por parte da comunidade escolar visando a priorização de ações de prevenção ao bullying na escola pesquisada, objetivando a garantia da saúde dos alunos, com ênfase em manter a qualidade da educação. Haja vista, que inúmeros alunos da escola estão expostos ao riscos de sofrerem abusos regulares de seus colegas.

Sensibilizar os envolvidos que o bullying pode trazer consequências irreparáveis para os alunos, torna-se, portanto uma tarefa de todos da comunidade escolar, visto que, tanto o agressor quanto a vitima venha receber o apoio necessário para que suas atitudes não possam vir a causar danos por toda a vida.

\section{REFERÊNCIAS}

BOCK, A. M. B. A perspectiva Sócio Histórica de Leontiev e a crítica à naturalização da formação do ser humano: a adolescência em questão. Caderno Cedes, Campinas, vol. 24, n. 62 , p. 26-43, abril 2004

BRASIL: Lei no 13.663, de 14 de maio de 2018. Dispõe sobre promoção de medidas de conscientização, de prevenção e de combate a todos os tipos de violência nos estabelecimentos de ensino. Disponivel em: http://www.planalto.gov.br/ccivil_03/_ ato2015-2018/2018/Lei/L13663.htm. Acesso em: 19 set. 2018.

Lei № 9.394, de 20 de Dezembro de 1996. Dispõe sobre a Lei de Diretrizes e Bases da Educação Nacional. Disponível em: http:// www.planalto.gov.br/ccivil_03/Leis/L9394. htm. Acesso em: 20 set. 2018.

Lei № 13.185, de 6 de Novembro de 2015. Institui o Programa de Combate à Intimidação Sistemática (Bullying). Disponível em: http://www.planalto.gov.br/ccivil_03/_ Ato2015-2018/2015/Lei/L13185.htm. Acesso em: 19 set. 2018.

Lei no 8.069, de 13 de julho de 1990. Dispõe sobre o Estatuto da Criança e do Adolescente e dá outras providências. Disponível em: < http://www.planalto.gov.br/ ccivil_03/leis/l8069.htm>. Acesso em: 19 set. 2018.

CALDAS, A. L. É preciso falar sobre bullyng. Agência Brasil. Brasília, 2017.

CALLINICOS, A. Capitalismo e racismo. Disponivel em: <http://www.iesc.ufrj.br/ cursos/saudepopnegra/ALEX\%20CALLINICOS_ Capitalismo\%20e\%20Racismo.pdf> acesso em: dez. 2018.

GIL, A. C. Como elaborar projetos de pesquisa. 4a ed. 7a tiragem. São Paulo: Atlas, 2009.

GRILLO, M. A.; SANTOS, A. C. S. Bullying na escola. Colloquium Humanarum. Jul-Set, V. 12, n. 3. p 61-74, 2015.

IBGE. Instituto Brasileiro de Geografia e estatística. Censo demográfico 2010. Disponivel em: https://censo2010.ibge.gov. br/. Acesso em: dez. 2018.

LOPES NETO, A. A. Bullying: Comportamento Agressivo entre Estudantes. Jornal de Pediatria, Rio Janeiro, v. 81, n. 5, supl. p. 164172, nov. 2005. Disponivel em: http://www. scielo.br/pdf/\%0D/jped/v81n5s0/v81n5Sa06. pdf. Acesso em: 20 set. 2018.

MARCOLINO, E. C.; CALVACANTI , A. L.; PADILHA, W. W. N.; MIRANDA, F. A. N.; CLEMENTINO, F. S. Bullying: prevalência e fatores associados à vitimização e à agressão no cotidiano escolar.

Texto Contexto Enferm, 2018. 
MARTINS, M. J. D. Prevenção da indisciplina, da violência e do bullying nas escolas. PROFFORMA. № 03 - Junho, 2011. Disponível em: http://www.cefopna.edu.pt/revista/ revista_03/pdf_03/es_01a_03.pdf. Acesso em: 20 set. 2018.

NIKODEM, S.; PIBER, L. D. Estudo sobre o fenômeno Bullying em escolas de ensino fundamental e médio da região noroeste do RS. Vivências. V.7, N.12: p.105-121, 2011.

SANTOS, U. C. L.; SILVA, P. F. Bullying escolar: Ausente na norma, presente na vida. Revista São Luís Orione. V. 2, N. 12, 2017. Disponível em: http://seer.catolicaorione.edu.br:81/index. $\mathrm{php} / \mathrm{revistaorione/issue/view/5.} \mathrm{Acesso} \mathrm{em:}$ 20 set. 2018.

SILVA, L. O.; BORGES, B. S. BULLYING NAS ESCOLAS. Direito \& Realidade. V. 6, n. 5, p.2740, 2018.

VENTURA, A.; FANTE, C. BULLYING: Intimidação no ambiente escolar e virtual. Belo Horizonte. Conexa, 2011.

ZEQUINÃO, M. A.; MEDEIROS, P. DE; PEREIRA, P; CARDOSO, F. L. Bullying escolar: um fenômeno multifacetado. Educ. Pesquisa, São Paulo, v. 42, n. 1, p. 181-198, jan./mar. 2016. 